\title{
Advanced Analysis of Quality of Picture and Picture Learning Model Reviewed from Moderator Variables Using JASP Software
}

\author{
Nurdiani Azzahrah'1, M. Ali Gufran ${ }^{2}$, Nurul Hikmah ${ }^{3}$, Syaharuddin ${ }^{*}$ \\ 1,2,3Tadris Matematika, Universitas Islam Negeri Mataram, Kota Mataram, Indonesia \\ ${ }^{4}$ Pendidikan Matematika, Universitas Muhammadiyah Mataram, Indonesia \\ nurdianiazzahra7@gmail.com ${ }^{1}$, aligufran327@gmail.com ${ }^{2}$, hikkmah62@gmail.com $^{3}$, \\ syaharuddin.ntb@gmail.com ${ }^{4}$
}

\section{ARTICLE INFO}

Article History:

Received : 07-04-2021

Revised : 01-05-2021

Accepted : 04-05-2021

Online : 05-05-2021

\section{Kata Kunci:}

Meta-analysis;

JASP software;

Picture and picture;

Learning outcomes.

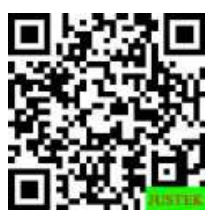

\section{ABSTRACT}

Abstrak: Penelitian ini bertujuan untuk mengetahui peningkatan kualitas pembelajaran menggunakan model picture and picture. Metode penelitian yang digunakan adalah penelitian meta-analisis dengan sumber data sekunder. Data dikumpulkan dari database pengindeks seperti dari Google Scholar, SINTA, dan Portal Garuda. Data yang difilter adalah hasil penelitian penelitian tindakan kelas yang memuat nilai ketuntasan klasikal, jumlah siswa yang tuntas, dan jumlah siswa yang menjadi subjek penelitian. Kemudian dianalisis menggunakan meta-analisis melalui nilai effect size dan standar error. Hasil analisis data menggunakan software JASP menunjukkan bahwa terdapat pengaruh yang signifikan terhadap hasil belajar menggunakan pembelajaran picture and picture sebesar 90\% dengan estimasi dampak 0,90 yang termaksud kategori tinggi dan 10\% disebabkan oleh faktor lainnya.

\begin{abstract}
This study aims to determine the improvement of the quality of learning using picture and picture models. The research method used is meta-analysis research with secondary data sources. Data is collected from indexer databases such as from Google Scholar, SINTA, and Garuda Portal. The filtered data is the result of a class action research study that contains classical completion values, the number of completed students, and the number of students who are the subjects of the study. It is then analyzed using meta-analysis through effect size values and standard errors. The results of data analysis using JASP software showed that there was a significant influence on learning outcomes using picture and picture learning by $90 \%$ with an estimated impact of 0.90 referred to as high category and $10 \%$ caused by other factors.
\end{abstract}

\section{A. LATAR BELAKANG}

Pendidikan merupakan usaha sadar dan terencana dalam mewujudkan proses pembelajaran dan suasana belajar agar peserta didik secara aktif mengembangkan potensi diri untuk memiliki kekuatan spiritual, keagamaan, pengendalian diri, kecerdasan, kepribadian, berakhlak mulia, serta memiliki keterampilan yang diperlukan peserta didik, ketika bermasyarakat, bangsa dan negara (Wedan, 2016). Tugas guru 
dalam pembelajaran adalah menjadikan peserta didik belajar melalui penciptaan strategi dan lingkungan belajar yang menarik dan bermakna (Sri Hastuti Noer, 2011). Pembelajaran dapat dikatakan berhasil apabila peserta didik dapat menerima dan menguasai materi dengan baik.

Dalam proses belajar mengajar, baik guru maupun siswa pasti mengharapkan agar mencapai hasil yang sebaik-baiknya (Utami, 2020). Dalam kenyataan, harapan itu tidak selalu terwujud, sebab masih banyak siswa yang tidak memperoleh hasil belajar yang memuaskan. Ada siswa yang mendapatkan nilai tinggi, ada pula yang mendapatkan nilai rendah, dan bahkan ada pula siswa yang harus tinggal dalam mencapai tujuan belajar. Dalam kegiatan pembelajaran siswa tidak hanya dituntut keaktifannya saja tapi juga kekreativitasannya, karena kreativitas dapat menciptakan situasi yang baru, tidak monoton dan menarik sehingga siswa akan lebih terlibat dalam kegiatan pembelajaran (Sulfemi \& Minati, 2018). Oleh sebab itu, guru menjadi salah satu orang yang bertanggung jawab secara langsung dalam menciptakan pembelajaran yang efektif dan diharuskan pula meningkatkan hasil belajar siswa.

Hasil belajar adalah ukuran kemampuan yang dimiliki peserta didik setelah mereka menerima proses belajar mengajar (Wondal, 2015). Penerapan model picture and picture, memberi kesempatan kepada siswa untuk saling berdiskusi tentang materi dalam bentuk gambar. Siswa akan lebih tertarik untuk mempelajari isi materi dari gambar yang ditampilkan, sehingga dapat meningkatkan hasil belajar siswa. Penelitian tentang penerapan pembelajaran model picture and picture dalam meningkatkan hasil belajar siswa sudah banyak dilakukan. Namun bagaimana tingkat pengaruh model ini pada setiap jenjang ataupun mata pelajaran belum diketahui. Oleh sebab itu, perlu analisis lanjutan terhadap hasil-hasil penelitian yang telah dilakukan tersebut.

Oleh sebab itu, dibutuh kanan alisis lebih lanjut dari hasil-hasil penelitian yang terkait dengan pengaruh model pembelajaran picture and picture menggunakan metaanalisis dalam meningkatkan hasil belajar siswa. Penelitian bertujuan untuk menunjukkan tingkat pengaruh pelaksanaan pembelajaran picture and picture terhadap hasil belajar siswa dijenjang Sekolah Dasar (SD), Sekolah Menengah Pertama (SMP), Sekolah Menengah Atas (SMA) maupun mata pelajaran Matematika, Ilmu Pengetahuan Sosial (IPS), dan Ilmu Pengetahuan Alam (IPA).

\section{B. METODE PENELITIAN}

Penelitian ini merupakan penelitian meta-analisi yang dilakukan peneliti dengan cara merangkum data penelitian, mereview dan menganalisis data penelitian dari beberapa hasil penelitian yang sudah ada sebelumnya (H. Mudjia Rahardjo, 2010). Bebrapa tahapan dalam menganalisi data yakni:

1. Variabel Bebas: Picture and picture

2. Variabel Terikat: Hasil Belajar

3. Melakukan pelabelan atau penomoran dan hasil seleksi artikel

4. Menulis nilai jumlah siswa (N), jumlah siswa yang tuntas (P),dan nilai klasikal (\%)

5. Menghitung nilai effect size (ES) dan standart error (SE) menggunakan rumus: 


$$
\begin{aligned}
& p=E S=\frac{l}{N} \\
& S E=\sqrt{\frac{p(1-p)}{N}}
\end{aligned}
$$

6. Melakukan analisis data menggunakan software JASP

7. Melakukan interpretasi terhadap hasil analisis data atau output dari software JASP

8. Menganalisis hasil-hasil yang ditemukan dari artikel-artikel yang menjadi rujukan data

9. Terakhir, mengambil kesimpulan-kesimpulan dari hasil penelitian.

\section{HASIL DAN PEMBAHASAN}

Hasil pencarian di Google Scholar ditemukan sebanyak 35 artikel yang berkaitan dengan kata kunci pembelajaran picture and picture terhadap hasil belajar. Dari seluruh artikel tersebut diseleksi berdasarkan criteria bahwa, hasil penelitian merupakan penelitian tindakan di dalam kelas. Hasil penelitian memuat nilai ketuntasan klasikal $(\mathrm{K})$, jumlah siswa yang tuntas (l), disebutkan jumlah siswa yang menjadi subjek penelitian (N), Effect size (ES) dan Standart Error (SE).

Tabel 1. Data Penelitian

\begin{tabular}{lcccc}
\hline \multicolumn{1}{c}{ Nama Penulis, Tahun } & N & L & ES & SE \\
\hline Barasano, 2017 & 30 & 27 & 0.9 & 0.054772 \\
\hline Andhika, 2016 & 20 & 17 & 0.85 & 0.079844 \\
\hline Susanti, 2017 & 25 & 22 & 0.88 & 0.064992 \\
\hline Fauziddin, 2018 & 25 & 24 & 0.96 & 0.039192 \\
\hline Kuraedah, 2016 & 23 & 19 & 0.826087 & 0.079034 \\
\hline Saenab, 2012 & 32 & 23 & 0.71875 & 0.07948 \\
\hline Endrayani, 2019 & 32 & 28 & 0.875 & 0.058463 \\
\hline Astuti, 2016 & 27 & 21 & 0.777778 & 0.080009 \\
\hline Sulfemi, 2018 & 38 & 32 & 0.842105 & 0.059153 \\
\hline Hartani, 2018 & 36 & 30 & 0.833333 & 0.062113 \\
\hline Sudrajat, 2016 & 29 & 26 & 0.896552 & 0.056552 \\
\hline Yunita, 2017 & 23 & 21 & 0.913043 & 0.058753 \\
\hline Mutmainah, 2012 & 26 & 24 & 0.923077 & 0.052259 \\
\hline Tembang, 2017 & 22 & 19 & 0.863636 & 0.073165 \\
\hline Hasanah, 2019 & 21 & 18 & 0.857143 & 0.07636 \\
\hline Zulbahri, 2020 & 32 & 17 & 0.53125 & 0.088216 \\
\hline Triwidjaja, 2014 & 7 & 6 & 0.857143 & 0.13226 \\
\hline Nisa, 2017 & 22 & 17 & 0.772727 & 0.089346 \\
\hline Nursalam, 2019 & 32 & 28 & 0.875 & 0.058463 \\
\hline Karmiani, 2018 & 21 & 17 & 0.809524 & 0.085689 \\
\hline Linarmawati, 2020 & 29 & 25 & 0.862069 & 0.064033 \\
\hline Kurniawan, 2017 & 23 & 21 & 0.913043 & 0.058753 \\
\hline Haris, 2019 & 33 & 31 & 0.939394 & 0.041536 \\
\hline
\end{tabular}




\begin{tabular}{lcccc}
\hline Seri, 2017 & 25 & 22 & 0.88 & 0.064992 \\
\hline Driarkoro, 2019 & 29 & 25 & 0.862069 & 0.064033 \\
\hline Dani, 2020 & 35 & 27 & 0.771429 & 0.070978 \\
\hline Tamrin, 2017 & 20 & 17 & 0.85 & 0.079844 \\
\hline Afifi, 2017 & 26 & 22 & 0.846154 & 0.070759 \\
\hline Nurhidaya, 2018 & 27 & 25 & 0.925926 & 0.050401 \\
\hline Nurhajati, 2020 & 30 & 26 & 0.866667 & 0.062063 \\
\hline Asih, 2019 & 30 & 26 & 0.866667 & 0.062063 \\
\hline Sugiyah, 2018 & 27 & 24 & 0.888889 & 0.060481 \\
\hline Apriani, 2016 & 20 & 18 & 0.9 & 0.067082 \\
\hline Hutabarat, 2018 & 33 & 27 & 0.818182 & 0.067141 \\
\hline Ratnaningsih, 2019 & 36 & 32 & 0.888889 & 0.052378 \\
\hline
\end{tabular}

Berdasarkan pada penelitian kami menemukan 19 data di SD, 12 data di SMP, 4 data di SMA. Pada mapel IPA sebanyak 13 data, pada mapel IPS sebanyak 17 data, pada mapel MTK sebanyak 5 data. Selanjutnya, penulis melakukan uji hipotesis dan uji publication bias terhadap data yang sudah di peroleh. Dalam meta-analisis menggunakan software JASP yang di lihat dalam penarikan kesimpulan adalah nilai $z$ dan $p$-value pada tabel coefficients. Adapun hipotesis sebagai berikut.

\section{Uji Hipotesis:}

1. Model pembelajaran picture and picture berpengaruh dalam meningkatkan hasil belajar pada siswa.

2. Model pembelajaran picture and picture berpengaruh dalam meningkatkan hasil belajar siswa berdasarkan jenjang pendidikan.

3. Model pembelajaran picture and picture berpengaruh dalam meningkatkan hasil belajar siswa berdasarkan mata pelajaran.

\section{Uji Publikasi Bias}

$H_{0}:$ true effect size $=0 \quad$ Penerapan model pembelajaran picture and picture tidak berpengaruh terhadap hasil belajar siswa, termasuk jenjang (SD, SMP, SMA) dan mata pelajaran (Matematika, IPA, IPS)

$H_{1}:$ true effect size $\neq 0 \quad$ Penerapan model pembelajaran picture and picture berpengaruh terhadap hasil belajar siswatermasuk jenjang (SD, SMP, SMA) dan mata pelajaran (Matematika, IPA, IPS)

Berdasarkan hasil simulasi diperoleh output JASP sebagai berikut.

\section{Uji Hipotesis}

Uji hipotesis dapat dilihat berdasarkan nilai z dan $p$-value pada tabel output JASP sesuai Tabel 2.

Tabel 2. Output JASP coefficients

\section{Coefficients}

\begin{tabular}{|c|c|c|c|c|}
\hline & \multicolumn{2}{|c|}{ Estimate Standard Error } & $\mathbf{Z}$ & $\mathbf{p}$ \\
\hline intercept & 0.872 & 0.011 & 78.31 & $<.001$ \\
\hline
\end{tabular}




\section{Coefficients}

\begin{tabular}{rrr}
\hline Estimate Standard Error & $\mathbf{z}$ & $\mathbf{p}$ \\
\hline
\end{tabular}

Note. Wald test.

Pada Tabel 2 tentang coefficients di atas, terlihat nilai $z$ sebesar 78.319 dan nilai p-value sebesar 0,001 yang berarti lebih kecil dari nilai signifikansi 5\% $(0,05)$. Ini berarti hipotesis $\mathrm{H0}$ ditolak, dalam hal ini true effect size tidak sama dengan 0 , dengan kata lain pembelajaran ini berpengaruh signifikan terhadap picture and picture terhadap hasil belajar.

\section{Uji Publikasi Bias}

Uji ini dilakukan untuk melihat apakah data yang sudah terkumpul dapat di jadikan sampe yang representatif dari populasinya. Uji ini dapat di lihat menggunakan nilai dari pada output Rank correlation dan regression method.

Tabel 3. Rank correlation

\section{Rank correlation test for Funnel plot asymmetry}

\begin{tabular}{lrl}
\hline & Kendall's $\boldsymbol{~}$ & p \\
\hline Rank test & -0.633 & $<.001$ \\
\hline
\end{tabular}

Tabel 4. Regression test

Regression test for Funnel plot asymmetry

("Egger's test")

\begin{tabular}{lcc}
\hline & $\mathbf{z}$ & $\mathbf{p}$ \\
\hline sei & -4.500 & $<.001$
\end{tabular}

Terkait Rank correlation terlihat nilai Kendall's sebesar -0.633 yang menunjukkan besar koefisien korelasi antara effect size dengan varians. Kemudian nilai $p$-value sebesar 0,001 lebih besar dari nilai 0,05 yang menunjukkan bahwa hipotesis $\mathrm{Ho}$ ditolak dengan kata lain tidak terindikasi publication bias. Pada Tabel diatas terlihat nilai $z$ yang merupakan besarnya koefisien regresi sebesar -4.500 , sedangkan nilai p-value sebesar 0,001lebih besar dari 0,05 yang menunjukkan bahwa hipotesis $\mathrm{H} 0$ ditolak dengan kata lain tidak terindikasi publication bias.

\section{File-safe $N$}

Tabel 5. File Drawer Analysis

File Drawer Analysis

Fail-safe N Target Significance Observed Significance

\begin{tabular}{lll}
\hline Rosenthal 81705.000 & 0.050 & $<.001$ \\
\hline
\end{tabular}

Tabel 5 di atas menunjukkan seberapa banyak penelitian yang memiliki ratarata effect size sama dengan 0 yang harus ditambahkan ke dalam sampel 
penelitian agar hasil penelitian terbebas dari publication bias. Berdasarkan Tabel diatas terlihat nilai Fail-safe N sebesar 81705 hasil publikasi yang harus ditambahkan. Nilai ini tidak menjadi wajib jika berdasarkan hasil Rank Correlation dan Regression Method sudah tidak terindikasi publication bias. Di samping itu untuk menguji publication bias dapat dilakukan dengan ketentuan jika nilai fail-safe $\mathrm{N}>5 \mathrm{~K}+10$ ( $\mathrm{K}=$ jumlah studi), maka dapat disimpulkan bahwa tidak terdapat bias publikasi. Dari Tabel 5 diperoleh $81705>5.45+10 \approx 21.912>$ 235. Jadi, sampel yang digunakan dalam penelitian ini terindikasi tidak adanya publication bias.

\section{Trim and fill}
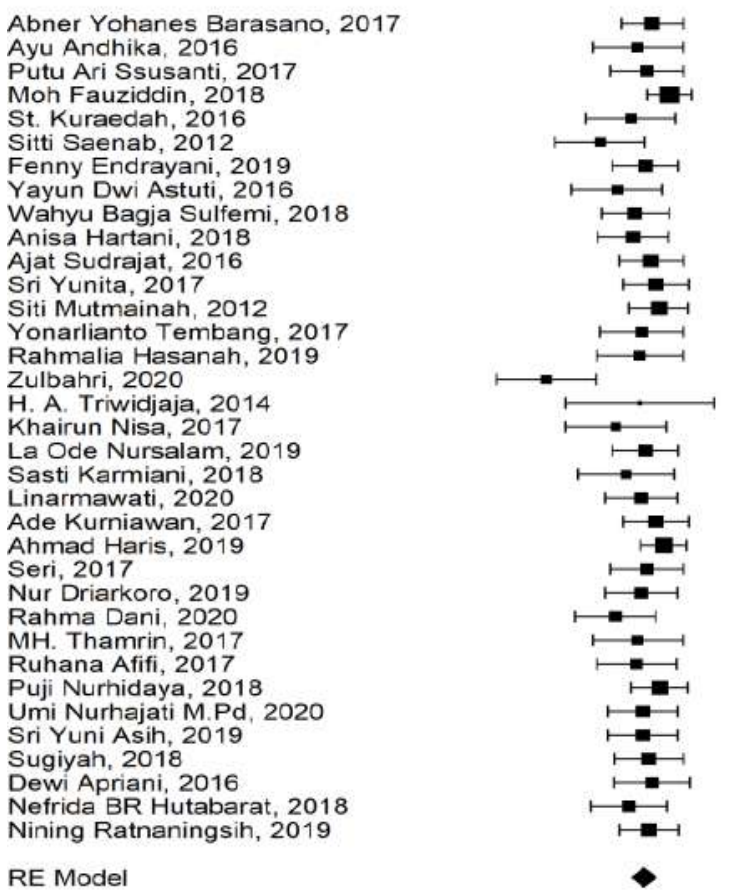

$0.90[0.79,1.01]$

$0.88[0.75,1.01$

$.96[0.88,1.04]$

$0.83[0.67,0.98]$

$0.72[0.56,0.87$

$0.88[0.76,0.99]$

$0.78[0.62,0.93]$

$0.84[0.73,0.96$

$0.83[0.71,0.96]$

$0.90[0.79,1.01]$

$0.91[0.80,1.03$

$0.86[0.72,1.01]$

$0.86[0.71,1.01]$

$0.53[0.36,0.70$

$0.86[0.60,1.12$

$0.77[0.60,0.95]$

$0.81[0.64,0.98]$

$0.86[0.74,0.99]$

$0.91[0.80,1.03$

94 . $86,1.02$

$0.88[0.75,101]$

$0.86[0.74,0.99]$

$0.77[0.63,0.91]$

$0.85[0.69,1.01$

.

$0.93[0.83,1.02]$

$0.87[0.75,0.99$

$0.89[0.77,1.01]$

$0.90[0.77,1.03$

$0.82[0.69,0.95]$

0.89 [0.79, 0.99]

$0.87[0.85,0.89]$

Gambar 1. Trim and Fill

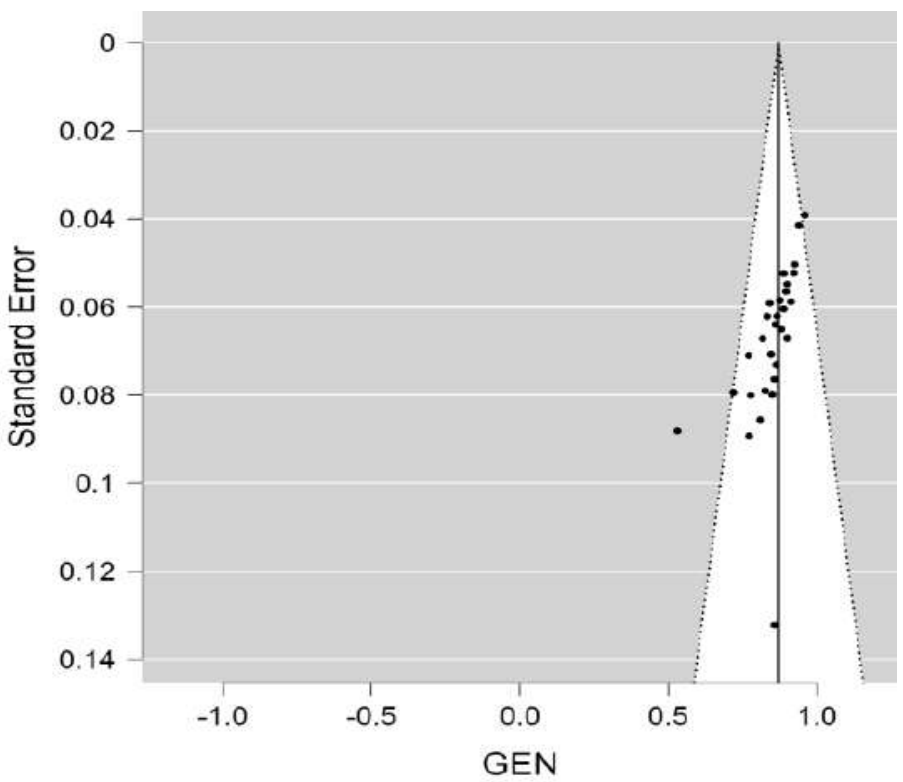

Gambar 2. Forest Plot 
Berdasarkan hasil ploting publikasi pada Gambar 1 di atas (paling atas) dapat diketahui bahwa tidak ada penelitian yang hilang yang ditandai lingkaran terbuka, seluruh lingkaran tertutup. Selanjutnya, dari Gambar 2 forest plot, diperoleh nilai summary effect sebesar 0,90 dengan kata lain pengaruh model pembelajaran picture and picture terhadap dan hasil belajar berpengaruh dalam meningkatkan hasil belajar siswa sebesar 90\% sedangkan 10\% dipengaruhi oleh factor yang lain.

Tabel 6. Variabel Moderator

\begin{tabular}{clrcrrl}
\hline & & & & & RE & \\
No & Karegori & Estimate & z & Kendall's & Models & Kategori \\
\hline 1 & SD & 0.887 & -2.777 & -0.541 & 0.88 & Sangat Kuat \\
\hline 2 & SMP & 0.873 & -1.849 & -0.75 & 0.87 & Sangat Kuat \\
\hline 3 & SMA & 0.76 & -3.589 & -1 & 0.76 & Kuat \\
\hline 4 & Matematika & 0.905 & -1.442 & -0.778 & 0.9 & Sangat Kuat \\
\hline 5 & IPA & 0.881 & -3.095 & 0.688 & 0.88 & Sangat Kuat \\
\hline 6 & IPS & 0.868 & -2.429 & -0.791 & 0.86 & Sangat Kuat \\
\hline
\end{tabular}

Dari Tabel 6 di atas, terlihat bahwa model pembelajaran picture and picture, terhadap hasil belajar sangat kuat pengaruhnya pada jenjang SD sebesar 0,88 atau $88 \%$. Selanjutnya pada jenjang SMP, pengaruh metode ini sebesar 0,87 atau 87\%. Artinya mungkin metode ini begitu berpengaruh terhadap peserta didik, sehingga metode ini tepat jika diterapkan kepada peserta didik di jenjang sekolah menengah pertama (SMP). Terakhir terhadap peserta didik di jenjang SMA, metode ini memberi pengaruh yang besar yakni 0,76 atau 76\%. Kemudian pada klasifikasi mata pelajaran, metode pembelajaran picture and picture ini kuat pengaruhnya pada mata pelajaran Matematika yaitu sebesar 0,90 atau 90\%, Pada Mata Pelajaran IPA pengaruh metode ini sebesar 0,88 atau $88 \%$, sedangkan pada Mata Pelajaran IPS pengaruh metode ini sebesar 0,86 atau 86\%. Persentase hasil belajar dengan metode ini terbukti dapat meningkatkan hasil belajar siswa. Artinya, penggunaan metode pembelajaran picture and picture terhadap hasil belajar sangat tepat jika digunakan dalam pembelajaran siswa pada setiap mata pelajaran.

\section{SIMPULAN DAN SARAN}

Berdasarkan uji hipotesis dan uji bias yang sudah dilakukan terhadap hasil-hasil penelitian mengenai pengaruh pembelajaran picture and picture terhadap hasil belajar berdasarkan mata pelajaran IPA, IPS, dan matematika pada jenjang SD, SMP, dan SMA berpengaruh sebesar $90 \%$ dengan estimasi dampak 0,90 yang termaksud kategori tinggi dan $10 \%$ disebabkan oleh faktor lainnya. Persentase hasil belajar dengan metode ini terbukti dapat meningkatkan hasil belajar siswa, Artinya dengan menggunakan metode pembelajaran picture and picture terhadap hasil belajar sangat tepat jika digunakan dalam pembelajaran siswa pada setiap mata pelajaran. 
Berdasarkan kesimpulan di atas peneliti memberikan saran yakni, guru mampu menerapkan model pembelajaran picture and picture terhadap dan hasil belajar guna dijadikan acuan dalam meningkatkan hasil belajar siswa. Selain itu, guru diharapkan menggunakan model pembelajaran yang tepat sesuai dengan mata pelajaran, sehingga siswa mampu dengan aktif untuk terlibat dalam kegiatan pembelajaran.

\section{REFERENSI}

Afzal, M. (2019). Efek Moderasi Kecerdasan Emosional Pada Hubungan Gaya Kepemimpinan Transformasional Dan Komitmen Organisasi Pada Badan .... Etd Unsyiah.

Apriani, K. (2016). Gambaran Kejadian Nyaris Cedera (Knc) Pada Pelayanan Kefarmasian Di Apotek Rawat Inap Rumkital Dr.Mintohardjo Periode April - Mei 2016. In Iosr Journal Of Economics And Finance (Vol. 3, Issue 1).

Astuti, L. (2016). Abstrak Leny Astuti. Revista Brasileira De Ergonomia, 9(2), 10.

Atiyatum Hasanah:2019. (2019). Analisis Kemampuan Penalaran Statistik Siswa Di Tinjau Dari Gaya Belajar 4mat System. Skripsi.

Atmaji, T. (2019). Media Pembelajaran Interaktif Melalui Permainan Tradisional Untuk Memperkuat Pendidikan Karakter. Prosiding Seminar Nasional "Penguatan Karakter Berbasis Literasi Ajaran Tamansiswa Menghadapi Revolusi Industri 4.0," September, 329-337.

Budi, A. S., \& Wardani, K. (2018). Implementasi Pendidikan Karakter Melalui Pemanfaatan Budayasekolah Di Sd Negeri Kyai Mojo Yogyakarta Tahun Ajaran 2016/2017. Trihayu: Jurnal Pendidikan Ke-Sd-An.

Budiarto \& Susanti, 2017. (2017). Pengaruh Financial Literacy, Overconfidence, Regret Aversion Bias, Danrisk Tolerance Terhadap Keputusan Investasi (Studi Pada Investor Pt. Sucorinvest Central Gani Galeri Investasi Bei Universitas Negeri Surabaya). Jurnal Ilmu Manajemen (Jim), 5(2), 1-9.

Chua, S.-A. (2016). Budget 2017: Budget 2017 At A Glance / The Edge Markets. The Edge Malaysia.

Darmawan, I. D. M. B. A. (2017). Implementasi Real Time Pitch Detection Untuk Mendeteksi Nada Kidung Bali Dengan Python. Seminar Nasional Sains Dan Teknologi Iv 2017, 29-36.

Dixon, S., Bornstein, J., Irshad, H., \& Pankratz, D. M. (2019). The 2019 Deloitte City Mobility Index. Deloitte Insights, 18.

Endrayani, F., Amaluddin, L. O., Mursalam, L. O., Musyawarah, R., \& Nyompa, S. (2020). Peningkatan Hasil Belajar Geografi Siswa Menggunakan Model Pembelajaran Kooperatif Tipe Picture And Picture. Unm Geographic Journal, 3(1), 79. Https://Doi.Org/10.26858/Ugj.V3i1.14603

Fauziddin, M., \& Mayasari, D. (2018). Pemanfaatan Metode Picture And Picture Untuk Meningkatkan Hasil Belajar Siswa Kelas Rendah Di Sekolah Dasar. Jurnal Pendidikan Tambusai, 2(2), 277. Https://Doi.Org/10.31004/Jpt.V2i2.674

Fitria, N., \& Tampubolon, I. L. (2020). The Effect Of Ginger Extract Consumption On Reducing Morning Sickness In First Trimester Of Pregnant Women At Pratama Mariana Clinic Medan, North Sumatra. Https://Doi.Org/10.26911/The7thicph.03.44

Fitriani, Y., \& Qurbaniah, M. (2018). Komparasi Model Example Non Example Dan Picture And Picture Terhadap Hasil Belajar Pada Sub Materi Tulang Sma N 2 Sungai Raya. Jurnal Bioeducation, 5(1). Https://Doi.Org/10.29406/999

H. Mudjia Rahardjo. (2010). Triangulasi Dalam Penelitian Kualitatif. Universitas Islam 
Negeri Maulana Malik Ibrahim Malang, October, 2-5.

Halliday, M. A. K., Matthiessen, C. M. I. M., Santosa, R., Priyanto, A. D., Nuraeni, A., Ellyawati, H. C., Rohmawati, I., Alvionita, R., Iedema, R., Feez, S., White, P. R. R. R., Painter, C., Sobhie, M., Reza Atai, M., Amin Mozaheb, M., Oleh, Komunikasi, J. I., Jurnal, L., Doi, L., ... Ahmadvand, M. (2016). Asociacion Entre Sobrepeso Y Obesidad Con Complicaciones Maternas En El Embarazo Y Puerperio En El Hospital General De Cuautitlan “General Jose Vicente Villada” Julio-Diciembre 2016. Nusa, 5(1), 1689-1699.

Hartono, H., \& Kusumastuti, L. A. (2019). Tingkat Kepatuhan Penggunaan Ramuan Jamu Saintifik Hiperglikemia Pada Pasien Diabetes Melitus Di Rumah Riset Jamu Hortus Medicus B2p2toot .... Jurnal Farmasi (Journal of ....

Istanti, A. W., \& Triwidjaja, H. A. (2014). Penerapan Model Pembelajaran Picture And Picture Pada Pembelajaran Ipa Anak Tunagrahita Sdlb. Universitas Negeri Malang, 169-174.

Karmiani, S. (2018). Penggunaan Media Komik Berbahasa Inggris Sebagai Upaya Meningkatkan Kemampuan Membaca Pemahaman Bahasa Inggris Pada Siswa Kelas Viii Smpn 3 Teluk Kuantan. Jurnal Pajar (Pendidikan Dan Pengajaran), 2(6), 883. Https://Doi.Org/10.33578/Pjr.V2i6.6514

Khairani Afifi Noordin. (2017). The Edge Sme Forum 2017: The Rise Of The Chatbots. The Edge Malaysia.

Kurniawan, A. (2017). (2017). Kekerasan Dan Maskulinitas Di Dalam Novel Eka Kurniawan : Seperti Dendam, Rindu Harus Dibayar Tuntas. Undip Journal, 1-42.

Labad, R., Hartani, T., \& Shinde, G. U. (2020). Effect Of Weed Treatment On Cereal Yield In Direct Seeding: A Challenge Between Soil Pollution And Seeds Quality. Indian Journal Of Agricultural Research, 54(1), 101-106. Https://Doi.Org/10.18805/Ijare.A-304

Linarmawati, L. (2020). Penerapan Model Picture And Picture Untuk Meningkatkan Aktivitas Dan Hasil Belajar Ipa Pada Materi Penggolongan Hewan Dan Tumbuhan Di Kelas Iii Min 8 Aceh Barat Daya. Jurnal Pendidikan Dan Pengabdian Vokasi (Jp2v), 1(1). Https://Doi.Org/10.32672/Jp2v.V1i1.2048

Mambrasar, Y. M., \& Hutabarat, P. W. K. (2018). Rhododendron Meagaii, A New Species Of Rhododendron Subgenus Vireya (Ericaceae) From Papua, Indonesia. Reinwardtia, 17(2). Https://Doi.Org/10.14203/Reinwardtia.V17i2.3570

Nursalam, 2016, Metode Penelitian. (2013). Renstra Klhk 2015-2019. Journal of Chemical Information And Modeling, 53(9), 1689-1699.

Pamungkas, G., \& Kurniasari, N. (2020). Hubungan Kelengkapan Sarana Dan Prasarana Puskesmas Dengan Kepuasan Pasien Di Puskesmas Melong Asih Kota Cimahi Tahun 2019. Jurnal Ilmu Kesehatan Immanuel, 13(2), 60. Https://Doi.Org/10.36051/Jiki.V13i2.92

Ratnaningsih, E. (2019). Kualitas Fungsi Seksual Ibu Postpartum Dengan Jahitan Perineum Diukur Menggunakan Female Sexual Function Index. Jurnal Smart Kebidanan, 6(2), 93. Https://Doi.Org/10.34310/Sjkb.V6i2.277

Saenab, S., \& Puspita, I. (2012). Peningkatan Aktivitas Dan Hasil Belajar Biologi Melalui Penerapan Model Pembelajaran Kooperatif Tipe Think Pair Share (Tps) Pada Siswa Kelas Xi Ipa 2 Sma Negeri 1 Mangkutana. Jurnal Bionature, 13(2), 127-135.

Setiawan, D. (2020). Quo \{Vadis\} \{Asas\} \{Legalitas\}: \{Penyimpangan\} \{Terhadap\} $\{$ Hukum $\}$ Acara $\}$ Pidana $\}$ Di $\{$ Tengah $\}$ PPandemi $\}$ Covid $\}-19$. In Rumpan.Id.

Setyaningsih, F. T. (2017). Penerapan Model Pembelajaran Kooperatif Tipe Picture And Picture Untuk Meningkatkan Motivasi Dan Hasil Belajar Siswa Kelas X Pmiia 2 Sma 
Xaverius Pringsewu Pada Materi Keanekaragaman Hayati. In Skripsi.

Sri Hastuti Noer. (2011). Mengembangkan Keterampilan Berpikir Kreatif. Jurnal $\begin{array}{lll}\text { Pendidikan } \quad \text { Matematika, } & \text { 5(1), }\end{array}$ Https://Doi.Org/10.1017/Cbo9781107415324.004

Sugiyah, \& Hl, S. (2019). Analisis Kualitas Pelayanan Tamu Pada Hotel Cabin Cabang Sutomo Yogyakarta. Eduturisma, Ii, 157.

Sulfemi, W. B., \& Minati, H. (2018). Meningkatkan Hasil Belajar Peserta Didik Kelas 3 Sd Menggunakan Model Picture And Picture Dan Media Gambar Seri. Jurnal Pendidikan Sekolah Dasar, 4(2), 228. Https://Doi.Org/10.30870/Jpsd.V4i2.3857

Surbakti, R. (2014). Pemilu Nasional Serentak 2019. In Rumah Pemilu. Universitas Brawijaya.

Surya, R. A. (2016). Ekstraksi Ciri Citra Batik Berdasarkan Tekstur Menggunakan Metode Gray Level Co Occurrence Matrix. Prosiding, 6 Desember 2016, Vol 2 No. 1, 2(1), 146-150.

Tempo.Co. (2017). 3 Serangan Teror Ini Diperintahkan Bachrun Naim Lewat Telegram. Tempo.Co.

Utami, F. N. (2020). Peran Guru Dalam Mengatasi Kesulitan Belajar Siswa Sekolah Dasar. Edukatif: Jurnal Ilmu Pendidikan, 2(1), 93-100. Https://Doi.Org/10.31004/Edukatif.V2i1.91

Wedan, M. (2016). Pengertian Pendidikan Dan Tujuan Pendidikan Secara Umum. Silabus.

Wondal, R. (2015). Pengaruh Media Pembelajaran Computer Assisted Instruction (Cai) Terhadap Hasil Belajar Siswa. Bioedukasi Universitas Khairun, 3(2).

Yunita, H., \& Soekiman, A. (2017). Analisis Tingkat Kepuasan Pengguna Jasa Konstruksi Terhadap Penerapan Sistem Manajemen Mutu Iso 9001:2008 Di Perusahaan Jasa Konstruksi. Konstruksia, 8(1), 35. Https://Doi.Org/10.24853/Jk.8.1.35-46

Zamanudin, M., Nurhajati, \& Hufron, M. (2019). Pengaruh Kompensasi, Lingkungan Kerja Dan Budaya Perusahaan Terhadap Kepuasan Kerja Karyawan Pada Perusahaan Daerah Air Minum Kota Malang. E-Jurnal Riset Manajemen Prodi Manajemen, 9(7), 76-92. 